\title{
Ocular hypotensive effects of a Rho-associated protein kinase inhibitor in rabbits
}

\author{
This article was published in the following Dove Press journal: \\ Clinical Ophthalmology \\ 31 March 2017 \\ Number of times this article has been viewed
}

\author{
Muhammad Irfan \\ Kamaruddin ${ }^{1,2}$ \\ Momoko Nakamura- \\ Shibasaki' \\ Yu Mizuno' \\ Yoshiaki Kiuchi' \\ 'Department of Ophthalmology and \\ Visual Sciences, Graduate School \\ of Biomedical Sciences, Hiroshima \\ University, Hiroshima, Japan; \\ ${ }^{2}$ Department of Ophthalmology, \\ Hasanuddin University, Makassar, \\ South Sulawesi, Indonesia
}

Purpose: Ripasudil is a novel Rho-associated protein kinase inhibitor that is used to treat ocular hypertension. However, the comparison of the intraocular pressure (IOP)-lowering effects between ripasudil alone and other ocular hypotensive drugs has not been studied thoroughly. The purpose of this study is to examine the ocular hypotensive effects of $0.4 \%$ ripasudil, $2 \%$ pilocarpine, $0.5 \%$ timolol and $0.1 \%$ dorzolamide in rabbits. We also studied the IOP changes when $0.4 \%$ ripasudil was combined with $2 \%$ pilocarpine, $0.5 \%$ timolol or $0.1 \%$ dorzolamide.

Methods: One drop of saline solution, $0.4 \%$ ripasudil, $0.5 \%$ timolol, $2 \%$ pilocarpine or $1 \%$ dorzolamide or a combination of these agents was applied topically to the left eyes of eight healthy albino rabbits. Posttreatment changes in the IOP of albino rabbits were monitored using a rebound tonometer over a 5-h time course. Changes in IOP after application of saline served as the control. One-way analysis of variance and Dunnett's post hoc tests were used for statistical analyses.

Results: After topical instillation, $0.4 \%$ ripasudil resulted in significant decreases in IOP at 0.5 and $1 \mathrm{~h}$ compared with the control group. Treatment with timolol, pilocarpine or dorzolamide had no significant effect on IOP. Treatment with timolol, pilocarpine or dorzolamide in combination with ripasudil resulted in significant reductions in IOP at $1 \mathrm{~h}$. However, none of these agents enhanced the IOP-lowering effects of ripasudil.

Conclusion: Ripasudil has stronger IOP-lowering effects than timolol, pilocarpine or dorzolamide hypotensive agents in our rabbit model. Addition of timolol, pilocarpine or dorzolamide did not enhance the IOP-lowering effects of ripasudil alone.

Keywords: ripasudil, timolol, pilocarpine, dorzolamide, intraocular pressure, rabbit

\section{Introduction}

Glaucoma is a common cause of irreversible blindness that is characterized by progressive retinal ganglion cell death, especially at the optic nerve head, resulting in visual field loss. ${ }^{1}$ Elevated intraocular pressure (IOP) can cause axonal damage to the optic nerve head and subsequent retinal ganglion cell death; therefore, elevation of IOP is considered a risk factor for multiple forms of glaucoma. ${ }^{2}$ Currently, many antiglaucoma drugs used clinically are designed to reduce IOP. Beta-blockers, such as timolol, reduce aqueous humor production by inhibiting the $\beta$-adrenoceptors in the ciliary body, resulting in a substantial and sustained reduction in IOP. ${ }^{3,4}$ Pilocarpine, a nonselective muscarinic receptor agonist that is the principal alkaloid derived from South American shrubs of the genus Pilocarpus, also reduces IOP. This agent induces contraction of the ciliary muscle, increasing the pull on the scleral spur and opening the trabecular meshwork, resulting in an increase in trabecular outflow. ${ }^{3,5}$ Carbonic anhydrase inhibitors, such as dorzolamide, inhibit the production of bicarbonate ions, reducing sodium and
Correspondence: Yoshiaki Kiuchi Department of Ophthalmology and Visual Sciences, Hiroshima University, I-2-3 Kasumi, Minami-ku, Hiroshima 734-855I, Japan

Tel $+8 I 822575247$

Fax +8I 822575249

Email ykiuchi@hiroshima-u.ac.jp
Clinical Ophthalmology 2017:II 59|-597

(c) (1) (2) ๑ 2017 Kamaruddin et al. This work is published and licensed by Dove Medical Press Limited. The full terms of this license are avaliable at https:/www.dovepress.com/terms.php cc) hereby accept the Terms. Non-commercial uses of the work are permitted without any further permisision from Dove Medical Press Limited, provided the work is properly attributed. For permission for commercial use of this work, please see paragraphs 4.2 and 5 of our Terms (https://www. doverperess.com/terms.php). 
fluid transport in the ciliary body, thus lowering IOP through suppression of aqueous humor production. . $^{3,6}$

Rho-associated coiled-coil-forming protein kinase (ROCK) is a downstream effector of the Rho family of GTPases. This kinase enzyme has been reported to reduce the contractility of ciliary smooth muscles by modulation of myosin phosphatase activity. ${ }^{7}$ In in vitro experiments using cultured cells derived from the trabecular meshwork and from Schlemm's canal, inhibition of Rho kinase activity was demonstrated to cause changes in actin cytoskeleton focal adhesion and cell-matrix and cell-cell interactions in such cells. ${ }^{8,9}$ Thus, ROCK inhibitors increase aqueous outflow by altering the permeability of Schlemm's canal, resulting in a substantial reduction in IOP. ROCK inhibitors decrease IOP by increasing aqueous outflow; however, the mechanism of action of these agents differs substantially to that of pilocarpine. ${ }^{10}$

The clinical use of eye drops containing more than one active agent with different mechanisms of action might result in enhanced IOP reduction relative to treatment with a single active agent. This study aimed to compare the ocular hypotensive effects of ripasudil, pilocarpine, timolol and dorzolamide in rabbit. We also examined the ocular hypotensive effects of the ROCK inhibitor ripasudil when combined with pilocarpine, dorzolamide or timolol in rabbits.

\section{Materials and methods}

\section{Animals}

The animals were housed and treated according to the Association for Research in Vision and Ophthalmology (ARVO) Statement for the Use of Animals in Ophthalmic and Vision Research. All animals used in this investigation were housed in animal facilities with a constant room temperature of $23^{\circ} \mathrm{C}$ with a 12-h light/12-h dark cycle (lights on at 08:00 h) for at least 7 days before measurements. All procedures performed in studies involving animals were approved by the Committee on Animal Experimentation and Committee of Research Facilities for Laboratory Animal Science at the Natural Science Center for Basic Research and Development at Hiroshima University. One eye from each of the eight 10- to 12-week-old male Japanese albino rabbits, each weighing $2-3 \mathrm{~kg}$, was used for all experimental sessions in this study.

\section{Chemicals}

Four types of antiglaucoma drugs were used in this study: $0.4 \%$ ripasudil hydrochloride hydrate (Kowa Company, Ltd., Nagoya Japan), 0.5\% timolol malate (Santen Pharmaceutical
Co., Ltd., Osaka, Japan), 2\% pilocarpine hydrochloride (Santen Pharmaceutical Co., Ltd.), and 1\% dorzolamide hydrochloride (Banyu Pharmaceutical Co., Ltd., Tokyo, Japan). Prostaglandin analogs have been proven to exhibit poor effect on ocular normotensive rabbits, and hence we did not use any such analogs in our study. ${ }^{11,12}$ All commercially available eye drops were applied to the rabbits' eyes without changing the formulation of the eye drops.

\section{Topical instillation of ocular hypotensive agents and placebo}

Each drug was administered to the eight eyes of eight rabbits, and IOPs were measured on the same day. One week later, the next session began using the next drug regime on the same animals. All drugs were initially administered as single agents. Following this initial administration, one of three combinations of agents was administered: first $0.4 \%$ ripasudil with $0.5 \%$ timolol; second, $0.4 \%$ ripasudil with $2 \%$ pilocarpine; and finally $0.4 \%$ ripasudil with $2 \%$ dorzolamide. Where combinations of agents were used, $0.4 \%$ ripasudil was administered first, followed 5 min later by administration of the second agent. Saline solution $(0.9 \% \mathrm{NaCl})$ was administered as the control treatment. The interval between the experimental sessions on each eye was 1 week.

\section{IOP measurement}

IOP was measured using a rebound tonometer (Tiolat Oy, Helsinki, Finland) according to the instruction manual; specifically, measurements were taken $6 \mathrm{~mm}$ from the center of the cornea with the probe perpendicular to the corneal plane. We converted the IOP readings from the rebound tonometer to the real IOP values using the equation obtained in prior experiments $^{13}$ :

True IOP $=1.63 \times($ rebound tonometer value $)+9.35$

Only the left eyes were used for experiments. IOP measurements were obtained prior to drug administration, and at $0.5,1,2$ and $5 \mathrm{~h}$ after topical application of either a saline solution or the ocular hypotensive agents. IOP was measured at each time point (each measurement consisting of a mean of seven IOP readings). All measurements of IOP were performed between 10:00 and 15:00 h.

\section{Statistical analyses and calculations}

Data were analyzed using a one-way analysis of variance (ANOVA) to assess the time course of changes in IOP over $5 \mathrm{~h}$ after instillation of each drug or drug combination. 
IOP in response to treatment with different agents was also compared between drugs used at each postoperative time point. If significant differences were observed following the ANOVA, Dunnett's post hoc test for multiple comparisons was performed to identify time points showing IOP values that were significantly different to baseline IOP levels or to the effects of the vehicle control $(0.9 \% \mathrm{NaCl})$. Data are expressed as the mean \pm standard deviation and mean difference. A $P$-value of $<0.05$ was considered statistically significant. Bonferroni's correction was used to adjust the $P$-values for multiple comparisons of individual time points. Statistical analyses were performed using SPSS statistical analysis software (SPSS Inc. Released 2007. SPSS for Windows, Version 16.0.; SPSS Inc., Chicago, IL, USA).

\section{Results}

IOP in the control group was higher at 0.5 and $1 \mathrm{~h}$ posttreatment, then started to decrease at $2 \mathrm{~h}$ and reached the lowest level at $5 \mathrm{~h}$ posttreatment (Figure 1). Eyes treated with either timolol, dorzolamide or pilocarpine showed a similar pattern of changes in IOP. In eyes treated with ripasudil, IOP started to decrease at $0.5 \mathrm{~h}$ and reached a minimum level at $1 \mathrm{~h}$, with an upward trend at 2 and $5 \mathrm{~h}$ posttreatment.

Eyes treated with the combination of timolol and ripasudil had the lowest IOP at $0.5 \mathrm{~h}$ posttreatment, with an upward

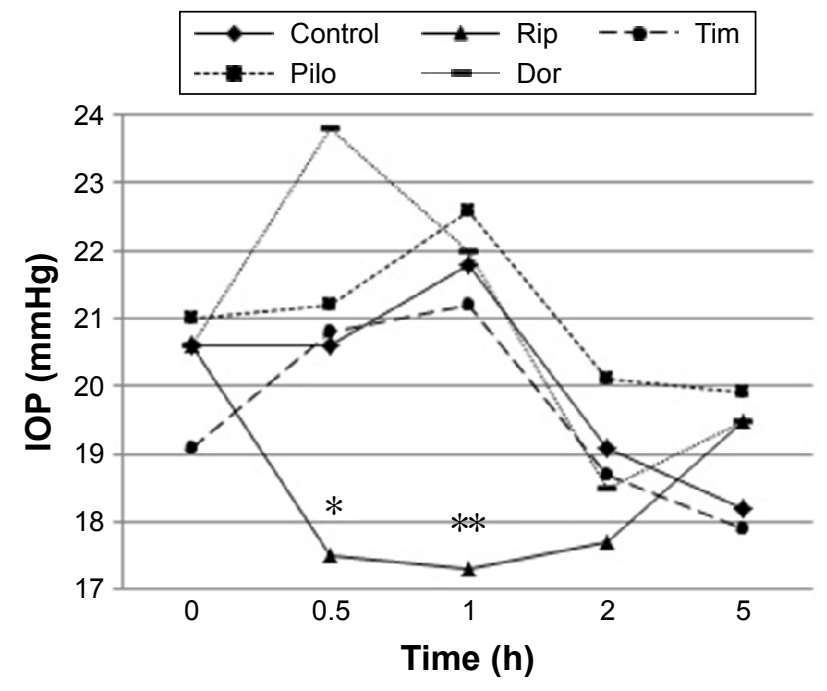

Figure I Time course of changes in IOP in rabbits treated with single agents. Notes: In the ripasudil group, IOP significantly decreased 0.5 posttreatment (*significant difference using Dunnett's test after Bonferroni's correction, $P=0.007$ ), reaching a minimum level at I h posttreatment (**significant difference using Dunnett's test after Bonferroni's correction, $P<0.000 \mathrm{I}$ ) with a trend toward increased IOP at 2-5 h posttreatment. Treatment with timolol or pilocarpine resulted in increased $\mathrm{IOP}$ at 0.5 to $\mathrm{I} \mathrm{h}$ posttreatment, followed by a decrease at $2 \mathrm{~h}$ posttreatment, reaching a minimum level at $5 \mathrm{~h}$ posttreatment. Effects of dorzolamide were similar to those of timolol or pilocarpine, although IOP had reached its maximum at $0.5 \mathrm{~h}$ posttreatment and minimum IOP at $2 \mathrm{~h}$ posttreatment.

Abbreviations: IOP, intraocular pressure; Rip, ripasudil; Tim, timolol; Pilo, pilocarpine; Dor, dorzolamide. observed between 1 and $5 \mathrm{~h}$ posttreatment. Eyes treated with either dorzolamide or pilocarpine in combination with ripasudil showed a downward trend in IOP from 0.5 to $2 \mathrm{~h}$, with an increase at $5 \mathrm{~h}$ posttreatment (Figure 2).

One-way ANOVA showed IOP after topical application of saline, ripasudil, timolol, dorzolamide and combination of ripasudil and timolol showed significant IOP changes (Table 1). The Dunnett's post hoc test for multiple comparisons revealed that $0.5,1$ and $2 \mathrm{~h}$ after combined ripasudil and timolol application, the IOP was significantly lower compared with IOP before application (significant difference using one-way ANOVA after Bonferroni's correction $P<0.0125$ ).

The comparison of all agents using a one-way ANOVA at each time point revealed significant differences in IOP at $0.5 \mathrm{~h}(P<0.0001)$ and $1 \mathrm{~h}(P<0.0001)$ posttreatment (Table 1$)$. Treatment with ripasudil $(P=0.007)$ resulted in significant reductions in IOP at $0.5 \mathrm{~h}$ posttreatment compared with IOP in the control group; however, treatment with timolol $(P=0.921)$, pilocarpine $(P=0.975)$, dorzolamide $(P=1.000)$, ripasudil plus timolol $(P=0.019)$, pilocarpine plus ripasudil ( $P=0.053$ ) or dorzolamide plus ripasudil $(P=0.083)$ had no significant effect upon IOP compared with controls. At $1 \mathrm{~h}$ posttreatment, treatment with ripasudil alone $(P<0.0001)$ and treatment with ripasudil plus timolol,

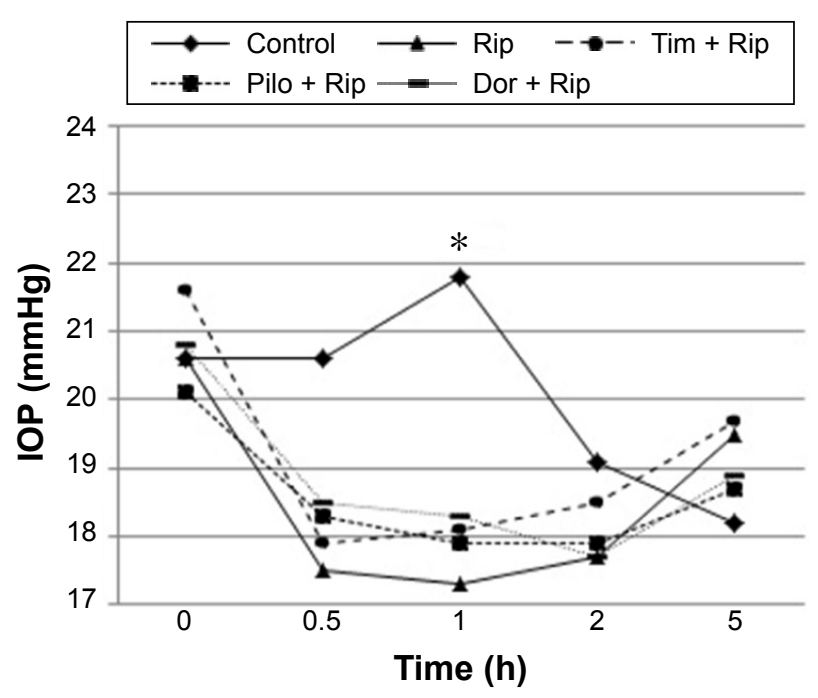

Figure 2 Time course of changes in IOP in rabbits treated with combinations of agents.

Notes: Treatment with the combination of timolol and ripasudil resulted in a decrease to the minimum IOP level at $0.5 \mathrm{~h}$ posttreatment with a trend toward increased IOP observed between I and $5 \mathrm{~h}$ posttreatment. Treatment with either dorzolamide or pilocarpine in combination with ripasudil resulted in a trend toward decreased IOP from 0.5 to $2 \mathrm{~h}$. At I h posttreatment, all combination groups have significant IOP differences compared to control (*significant difference using Dunnett's test after Bonferroni's correction, $P<0.007$ I).

Abbreviations: IOP, intraocular pressure; Rip, ripasudil; Tim, timolol; Pilo, pilocarpine; Dor, dorzolamide. 
Table I IOP changes after installation of each agent

\begin{tabular}{|c|c|c|c|c|c|c|c|c|c|}
\hline \multirow{2}{*}{$\begin{array}{l}\text { Time } \\
\text { course }\end{array}$} & \multicolumn{8}{|l|}{ Agents } & \multirow[t]{2}{*}{$P$-value } \\
\hline & $\mathrm{NaCl}$ & Rip & Tim & Pilo & Dor & Tim + Rip & Pilo + Rip & Dor + Rip & \\
\hline $\mathrm{Oh}$ & $20.6 \pm 2.9$ & $20.6 \pm 2.5$ & $19.1 \pm 1.2$ & $21.0 \pm 2.0$ & $20.6 \pm 2.0$ & $21.6 \pm 1.5$ & $20.1 \pm 2.1$ & $20.8 \pm 3.4$ & 0.643 \\
\hline $0.5 \mathrm{~h}$ & $20.6 \pm 1.8$ & $17.5 \pm 2.1$ & $20.8 \pm 2.1$ & $21.2 \pm 2.1$ & $23.8 \pm 2.0$ & $17.9 \pm 1.4$ & $18.3 \pm 1.9$ & $18.5 \pm 1.2$ & $<0.000$ I* \\
\hline $\mathrm{I} \mathrm{h}$ & $21.8 \pm 2.3$ & $17.3 \pm 1.8$ & $21.2 \pm 0.8$ & $22.6 \pm 2.7$ & $22.0 \pm 3.0$ & $\mid 8.1 \pm 1.5$ & $17.9 \pm 1.7$ & $18.3 \pm 2.3$ & $<0.000$ I* \\
\hline $2 \mathrm{~h}$ & $19.1 \pm 1.2$ & $17.7 \pm 2.7$ & $18.7 \pm 1.9$ & $20.1 \pm 2.7$ & $18.5 \pm 2.1$ & $18.5 \pm 0.8$ & $17.9 \pm 2.4$ & $17.7 \pm 2.0$ & 0.294 \\
\hline $5 \mathrm{~h}$ & $18.5 \pm 1.2$ & $19.5 \pm 1.4$ & $17.9 \pm 0.8$ & $19.9 \pm 2.6$ & $19.5 \pm 1.2$ & $19.7 \pm 1.7$ & $18.7 \pm 2.1$ & $18.9 \pm 1.4$ & 0.2 \\
\hline$P$-value & $0.022 * *$ & $0.016 * *$ & $<0.000 I^{* *}$ & 0.225 & $<0.000 I^{*} * *$ & $<0.000 I^{* *}$ & 0.199 & 0.084 & - \\
\hline
\end{tabular}

Notes: The data are expressed as mean \pm SD. The number of rabbits was $8 . \mathrm{NaCl}, \mathrm{NaCl} 0.9 \%$; Rip, ripasudil $0.4 \%$; Tim, timolol $0.5 \%$; Pilo, pilocarpine $2 \%$; Dor, dorzolamide $2 \%$; Tim + Rip, combination of timolol $0.5 \%$ and ripasudil $0.4 \%$; Pilo + Rip, combination of pilocarpine $2 \%$ and ripasudil $0.4 \%$; Dor + Rip, combination of dorzolamide $2 \%$ and ripasudil $0.4 \%$. *Significant difference using one-way ANOVA among all treatment groups $(P<0.05)$. **Significant difference compared to the IOP before treatment using one-way ANOVA $(P<0.05)$.

Abbreviations: IOP, intraocular pressure; ANOVA, analysis of variance; SD, standard deviation.

pilocarpine or dorzolamide (all $P<0.0071$ ) all resulted in statistically significant reductions in IOP compared with controls (Table 2).

Comparisons of the effects of ripasudil alone versus those of ripasudil in combination with timolol, pilocarpine or dorzolamide revealed significant differences in IOP $2 \mathrm{~h}$ after topical application. However, no statistically significant differences were observed after correction for multiple comparisons (Table 3).

\section{Discussion}

In this study, application of the control solution resulted in a transient increase in IOP at $1 \mathrm{~h}$ after the initial IOP measurement ( $3 \mathrm{~h}$ after lights on), followed by a gradual decrease in

Table 2 Comparison of IOP between control and ocular hypotensive agents

\begin{tabular}{llll}
\hline $\begin{array}{l}\text { Time points } \\
\text { (h) }\end{array}$ & Agents (I) & $\begin{array}{l}\text { IOP } \\
(\mathbf{m m H g})\end{array}$ & $\begin{array}{l}\text { P compared with } \\
\text { each control }\end{array}$ \\
\hline 0.5 & Control $(\mathrm{NaCl})$ & 20.6 & - \\
& Rip & 17.5 & $0.007^{*}$ \\
& Tim & 20.8 & 0.921 \\
& Pilo & 21.2 & 0.975 \\
& Dor & 23.8 & $\mathrm{I}$ \\
& Tim + Rip & 17.9 & 0.019 \\
& Pilo + Rip & 18.3 & 0.053 \\
& Dor + Rip & 18.5 & 0.083 \\
& Control $(\mathrm{NaCl})$ & 21.8 & - \\
& Rip & 17.3 & $<0.000 I^{*}$ \\
& Tim & 21.2 & 0.683 \\
& Pilo & 22.6 & 0.983 \\
& Dor & 22 & 0.918 \\
& Tim + Rip & 18.1 & $0.003^{*}$ \\
& Pilo + Rip & 17.9 & $0.002^{*}$ \\
& Dor + Rip & 18.3 & $0.005^{*}$ \\
\hline
\end{tabular}

Notes: The number of rabbits was $8 . \mathrm{NaCl}, \mathrm{NaCl} 0.9 \%$; Rip, ripasudil $0.4 \%$; Tim, Timolol $0.5 \%$; Pilo, pilocarpine $2 \%$; Dor, dorzolamide $2 \%$; Tim + Rip, combination of Timolol $0.5 \%$ and ripasudil $0.4 \%$; Pilo + Rip, combination of pilocarpine $2 \%$ and ripasudil $0.4 \%$; Dor + Rip, combination of dorzolamide $2 \%$ and ripasudil $0.4 \%$. *Significant difference using Dunnett's test after Bonferroni's correction $(P<0.007 \mathrm{I})$.

Abbreviation: IOP, intraocular pressure.
IOP. This effect might be explained by the diurnal changes in IOP in the rabbits used in our study. These changes in IOP are somewhat different to those described in previous reports and we are unable to clarify the reasons for the variations. ${ }^{14}$ Treatment with timolol, pilocarpine or dorzolamide had no significant effects on IOP, and the fluctuations in IOP were similar to those observed in the control group. Treatment with ripasudil either alone or in combination with other agents resulted in significant reductions in IOP. These differences reached a maximum of $4.5 \mathrm{mmHg}$ relative to controls at $1 \mathrm{~h}$ posttreatment. The combination of timolol, pilocarpine or dorzolamide with ripasudil resulted in significant reductions in IOP compared with controls at the $1 \mathrm{~h}$ time point. These data indicate that ripasudil is more effective than timolol, pilocarpine or dorzolamide in terms of reducing IOP in rabbits. Despite the significant effects of ripasudil in combination with other agents, the decrease in IOP induced by ripasudil alone was similar to that of any combination therapy.

Data from many studies indicate that ROCK mediates contraction of the trabecular meshwork ${ }^{15,16}$ and that inhibition of ROCK results in a substantial reduction in IOP in rabbits. ${ }^{8,17,18}$ One ROCK inhibitor, H-1152P, has been

Table 3 Comparison of IOP between ripasudil monotherapy and combination therapy

\begin{tabular}{|c|c|c|c|c|c|}
\hline \multirow{2}{*}{$\begin{array}{l}\text { Time } \\
\text { course }(h)\end{array}$} & \multicolumn{4}{|l|}{ Agents } & \multirow[t]{2}{*}{$P$-value } \\
\hline & Rip & Tim + Rip & Pilo + Rip & Dor + Rip & \\
\hline 0 & $20.6 \pm 2.5$ & $21.6 \pm 1.5$ & $20.1 \pm 2.1$ & $20.8 \pm 3.4$ & 0.827 \\
\hline 0.5 & $17.5 \pm 2.1$ & $17.9 \pm 1.4$ & $18.3 \pm 1.9$ & $18.5 \pm 1.2$ & 0.859 \\
\hline I & $\mid 7.3 \pm 1.8$ & $\mid 8.1 \pm 1.5$ & $\mid 7.9 \pm 1.7$ & $18.3 \pm 2.3$ & 0.907 \\
\hline 2 & $17.7 \pm 2.7$ & $18.5 \pm 0.8$ & $17.9 \pm 2.4$ & $17.7 \pm 2.0$ & $0.028^{*}$ \\
\hline 5 & $19.5 \pm 1.4$ & $19.7 \pm 1.7$ & $|8.7 \pm 2|$. & $\mid 8.9 \pm 1.4$ & 0.759 \\
\hline
\end{tabular}

Note: *Significant difference using one-way ANOVA among all treatment groups $(P<0.05)$.

Abbreviations: IOP, intraocular pressure; Rip, ripasudil; Tim, timolol; Pilo, pilocarpine; Dor, dorzolamide; ANOVA, analysis of variance. 
demonstrated to result in a significant, long-lasting, dosedependent reduction in IOP in the eyes of rabbits with no underlying pathology. ${ }^{18}$ ROCK inhibition relaxes vascular smooth muscle cells by rendering them less sensitive to intracellular $\mathrm{Ca}^{2+}$. A similar effect upon trabecular meshwork cells might explain the increased trabecular outflow and reduction in IOP produced by ROCK inhibition. ${ }^{19}$ In our study, topical application of timolol alone had no significant effect on IOP. This lack of an effect might be explained by the fact that, in rabbits, aqueous humor production and IOP are regulated by circadian rhythms. In the 12-h light/12-h dark cycle used in this study, IOP of the rabbits is relatively low during the light phase and relatively high during the dark phase. ${ }^{14}$ We applied timolol during the light phase, $2 \mathrm{~h}$ after the light being switched on. However, timolol is largely ineffective in rabbits during the light phase. ${ }^{20}$ This ineffectiveness of timolol in reducing IOP in rabbits suggests that tonic adrenergic stimulation of aqueous humor production is weak during the light phase. ${ }^{21,22}$ This effect might explain the lack of any significant IOP-lowering effects of timolol and might also explain the lack of an additive IOP-lowering effect when combined with ripasudil.

Our study shows that both pilocarpine and dorzolamide also had no significant effects on IOP when applied as single agents. Dorzolamide has been reported to decrease IOP in rabbits during both dark and light phases. Sugrue et $\mathrm{al}^{23}$ reported that the IOP of normotensive, conscious, albino rabbits significantly decreased, with a maximum reduction in IOP of $3.3 \mathrm{mmHg}$ occurring at $1 \mathrm{~h}$ after topical administration of a single drop of dorzolamide. Nagata et $\mathrm{al}^{24}$ detected a decrease in IOP after topical application of pilocarpine to the eyes of albino rabbits in the light phase. We have no obvious explanation for the lack of a reduction in IOP observed with dorzolamide and pilocarpine in our study. Sugrue et $\mathrm{al}^{23}$ and Nagata et $\mathrm{al}^{24}$ measured IOP using an applanation pneumatonograph driven by chlorofluorocarbons (CFCs), which allowed IOP values to be obtained continuously for a few seconds. Applanation pneumatonograph, using CFCs, provides reliable measurements of IOP in experimental animals. However, CFCs can no longer be used freely owing to the risks of damage to the environment by this class of compounds. Dinslage et $\mathrm{al}^{25}$ used implantable pressure monitors to measure the effects of several ocular hypotensive drugs on IOP in rabbits: these investigators showed that a $2 \%$ pilocarpine solution has no significant effects on IOP whereas treatment with $2 \%$ dorzolamide results in a significant reduction in IOP. Takenaka et $\mathrm{al}^{26}$ measured IOP in the eyes of rabbits using a Tonopen $\mathrm{XL}^{\circledR}$ applanation tonometer, a Perkins tonometer and a rebound tonometer. These researchers showed the Pearson correlation coefficients between the true IOP obtained using a pressure transducer and the IOPs measured using the Tonopen XL tonometer, the Perkins tonometer or the rebound tonometer were $0.83,0.96$ and 0.97 , respectively. IOPs measured using the rebound tonometer had the smallest variations from the pressure transducer readings, followed by those obtained using the Perkins tonometer and the Tonopen XL tonometer. These researchers concluded that the rebound tonometer is the most effective for measurement of IOP in rabbit models of glaucoma. No published data are available comparing the reliability and accuracy of the rebound tonometer with that of the pneumatonograph. Differences in the type of tonometry used to measure IOP might explain these variable results.

Tanihara et $\mathrm{al}^{27}$ found that both timolol and latanoprost have an additive IOP-lowering effect when combined with ripasudil in humans. The mechanisms of action of timolol and latanoprost are each distinctly different from that of ripasudil: timolol reduces aqueous humor production and latanoprost acts by enhancing uveoscleral outflow. In our study, although the combination of ripasudil with other drugs with ocular hypotensive effects resulted in significant reductions in IOP compared with controls, the coadministration of timolol, dorzolamide or pilocarpine with ripasudil did not enhance the IOP-lowering effects of ripasudil in our model.

In this study, treatment with ripasudil resulted in a significant reduction in IOP in rabbit eyes. This strong effect of ripasudil might have masked the weaker IOPlowering effects of timolol, pilocarpine or dorzolamide when combined with ripasudil. Furthermore, physiological differences between rabbit and human eyes may also have affected the relevance of these findings to human patients. Yamagishi et $\mathrm{al}^{28}$ evaluated the interactions of ripasudil with pilocarpine when applied concomitantly in mice. These investigators were unable to demonstrate additive IOP-lowering effects of pilocarpine when used with ripasudil. These investigators speculated that interactions between the effects of ripasudil and pilocarpine on aqueous outflow pathways in the trabecular meshwork diminished the IOP-lowering effects of each agent, based on the findings of immunohistochemical analysis of cells of the trabecular meshwork. Species differences in the responses of animals to experimental drugs will remain a challenge to drug discovery programs that aim to identify new treatments for human diseases.

In this study, we used rabbits with IOP levels in the normal range and measured IOP during the light phase, 
during which IOP is generally lower than that in the dark phase. The use of ocular normotensive rabbits is potentially a limitation of our study. Gupta et $\mathrm{al}^{29}$ compared the effects of three ocular hypotensive agents and showed that the peak IOP-lowering effects of pilocarpine, timolol and latanoprost in normotensive rabbit eyes were $18.23 \%, 20 \%$ and $22.56 \%$, respectively. However, in water-loaded rabbits, latanoprost (40.27\%) conferred the highest level of protection against elevated IOP, followed by timolol (31.39\%) and pilocarpine (28.91\%). This study demonstrates that increasing IOP using water-loading results in greater reductions in IOP by ocular hypotensive agents. However, the relative effects were similar to those in normotensive rabbit eyes.

ROCK inhibitors are a new type of antiglaucoma drug, with a distinctly different mechanism of action to those of other established ocular hypotensive agents. Our study revealed that ripasudil has a strong ocular hypotensive effect compared with that of pilocarpine, timolol or dorzolamide in our rabbit model. The addition of timolol, pilocarpine or dorzolamide to ripasudil did not enhance the IOP-lowering effects of ripasudil in normal albino rabbits. The different responses to ripasudil observed in human and animal eyes require further research. We have discussed our results in the context of different animal models, different tonometers and the different actions of IOP lowering drugs. Further research in elucidating the pharmacology of ROCK inhibitors in different models will result in a better understanding of ripasudil and lead to more effective treatment of patients with glaucoma.

\section{Disclosure}

The authors report no conflicts of interest in this work.

\section{References}

1. Foster PJ, Buhrmann R, Quigley HA, Johnson GJ. The definition and classification of glaucoma in prevalence surveys. Br J Opthalmol. 2002; 86(2):238-242.

2. Asrani S, Zeimer R, Wilensky J, Gieser D, Vitale S, Lindenmuth K. Large diurnal fluctuations in intraocular pressure are an independent risk factor in patients with glaucoma. J Glaucoma. 2000;9(2):134-142.

3. Coakes RL, Brubaker RF. The mechanism of timolol in lowering intraocular pressure in the normal eye. Arch Ophthalmol. 1978;96(11): 2045-2048.

4. Saxena R, Prakash J, Gupta SK, Mathur P. Pharmacotherapy of glaucoma. Indian J Pharmacol. 2002;34(2):71-85.

5. Gaasterland D, Kupfer C, Ross K. Studies of aqueous humor dynamics in man, IV: effects of pilocarpine upon measurements in young normal volunteers. Invest Ophthalmol. 1975;14(11):848-853.

6. Lippa EA, Carlson LE, Ehinger B, et al. Dose response and duration of action of dorzolamide, a topical carbonic anhydrase inhibitor. Arch Ophthalmol. 1992;110(4):495-459.

7. Waki M, Yoshida Y, Oka T, Azuma M. Reduction of intraocular pressure by topical administration of an inhibitor of the Rho-associated protein kinase. Curr Eye Res. 2001;22(6):470-474.
8. Tokushige H, Inatani M, Nemoto S, et al. Effects of topical administration of y-39983, a selective rho-associated protein kinase inhibitor, on ocular tissues in rabbits and monkeys. Invest Ophthalmol Vis Sci. 2007;48(7):3216-3222.

9. Tanihara $\mathrm{H}$, Inatani $\mathrm{M}$, Honjo $\mathrm{M}$, Tokushige $\mathrm{H}$, Azuma J, Araie M. Intraocular pressure-lowering effects and safety of topical administration of a selective ROCK inhibitor, SNJ-1656, in healthy volunteers. Arch Ophthalmol. 2008;126(6):309-315.

10. Tanihara H, Inoue T, Yamamoto T, et al; K-115 Clinical Study Group. Phase 2 randomized clinical study of a Rho kinase inhibitor, $\mathrm{K}-115$, in primary open-angle glaucoma and ocular hypertension. Am J Ophthalmol. 2013;156(4):731-736.

11. Orihashi M, Shima Y, Tsuneki H, Kimura I. Potent reduction of intraocular pressure by nipradilol plus latanoprost in ocular hypertensive rabbits. Biol Pharm Bull. 2005;28(1):65-68.

12. Impagnatiello F, Borghi V, Gale DC, et al. A dual acting compound with latanoprost amide and nitric oxide releasing properties, shows ocular hypotensive effects in rabbits and dogs. Exp Eye Res. 2011; 93(3):243-249.

13. Nakamura-Shibasaki M, Latief MA, Ko JA, Funaishi K, Kiuchi Y. Effects of topical adrenergic agents on prostaglandin E2-induced aqueous flare and intraocular pressure elevation in pigmented rabbits. Jpn J Ophthalmol. 2016;60(2):95-102.

14. Braslow RA, Gregory DS. Adrenergic decentralization modifies the circadian rhythm of intraocular pressure. Invest Ophthalmol Vis Sci. 1987; 28(10): 1730-1732.

15. Honjo M, Tanihara $\mathrm{H}$, Inatani M, et al. Effects of rho-associated protein kinase inhibitor Y-27632 on intraocular pressure and outflow facility. Invest Ophthalmol Vis Sci. 2001;42(1):137-144.

16. Van de Velde S, Van Bergen T, Sijnave D, et al. AMA0076, a novel, locally acting Rho kinase inhibitor, potently lowers intraocular pressure in New Zealand white rabbits with minimal hyperemia. Invest Ophthalmol Vis Sci. 2014;55(2):1006-1016.

17. Fukunaga T, Ikesugi K, Nishio M, et al. The effect of the Rho-associated protein kinase inhibitor, HA-1077, in the rabbit ocular hypertension model induced by water loading. Curr Eye Res. 2009;34(1):42-47.

18. Nishio M, Fukunaga T, Sugimoto M, et al. The effect of the H-1152P, a potent Rho-associated coiled coil-formed protein kinase inhibitor, in rabbit normal and ocular hypertensive eyes. Curr Eye Res. 2009; 34(4):282-286.

19. Williams RD, Novack GD, van Haarlem T, Kopczynski C; AR-12286 Phase 2A Study Group. Ocular hypotensive effect of the Rho kinase inhibitor AR-12286 in patients with glaucoma and ocular hypertension. Am J Ophthalmol. 2011;152(5):834-841.

20. Percicot CL, Schnell CR, Debon C, Hariton C. Continuous intraocular pressure measurement by telemetry in alpha-chymotrypsin-induced glaucoma model in the rabbit: effects of timolol, dorzolamide, and epinephrine. J Pharmacol Toxicol Methods. 1996;36(4):223-228.

21. Vareilles P, Silverstone D, Plazonnet B, Le Douarec JC, Sears ML, Stone CA. Comparison of the effects of timolol and other adrenergic agents on intraocular pressure in the rabbit. Invest Ophthalmol Vis Sci. 1977;16(11):987-996.

22. Bartels SP, Roth HO, Jumblatt MM, Neufeld AH. Pharmacological effects of topical timolol in the rabbit eye. Invest Ophthalmol Vis Sci. 1980;19(10):1189-1197.

23. Sugrue MF, Mallorga P, Schwam H, Baldwin JJ, Ponticello GS. A comparison of L-671,152 and MK-927, two topically effective ocular hypotensive carbonic anhydrase inhibitors, in experimental animals. Curr Eye Res. 1990;9(6):607-615.

24. Nagata A, Mishima HK, Kiuchi Y, Hirota A, Kurokawa T, Ishibashi S. Binding of antiglaucomatous drugs to synthetic melanin and their hypotensive effects on pigmented and nonpigmented rabbit eyes. Jpn J Ophthalmol. 1993;37(1):32-38.

25. Dinslage $\mathrm{S}, \mathrm{McLaren} \mathrm{J}$, Brubaker R. Intraocular pressure in rabbits by telemetry II: effects of animal handling and drugs. Invest Ophthalmol Vis Sci. 1998;39(12):2485-2489. 
26. Takenaka J, Mochizuki H, Kunihara E, Tanaka J, Kiuchi Y. Evaluation of rebound tonometer for measuring intraocular pressure at deviated angle and position. Curr Eye Res. 2011;36(5):422-428.

27. Tanihara H, Inoue T, Yamamoto T, et al; K-115 Clinical Study. Additive intraocular pressure-lowering effects of the Rho kinase inhibitor ripasudil (K-115) combined with timolol or latanoprost: a report of 2 randomized clinical trials. JAMA Ophthalmol. 2015;133(7):755-761.

28. Yamagishi R, Honjo M, Aoyama Y, Uchida T, Aihara M. Altered interactions of concomitant administrations of ROCK inhibitor and para sympathetic agonist in mouse IOP and outflow dynamics. Invest Ophthalmol Vis Sci. 2016; E-abstract 3011.
29. Gupta SK, Agarwal R, Galpalli ND, Srivastava S, Agrawal SS, Saxena R. Comparative efficacy of pilocarpine, timolol and latanoprost in experimental models of glaucoma. Methods Find Exp Clin Pharmacol. 2007;29(10):665-671.

\section{Publish your work in this journal}

Clinical Ophthalmology is an international, peer-reviewed journal covering all subspecialties within ophthalmology. Key topics include: Optometry; Visual science; Pharmacology and drug therapy in eye diseases; Basic Sciences; Primary and Secondary eye care; Patien Safety and Quality of Care Improvements. This journal is indexed on

Submit your manuscript here: http://www.dovepress.com/clinical-ophthalmology-journal

\section{Dovepress}

PubMed Central and CAS, and is the official journal of The Society of Clinical Ophthalmology (SCO). The manuscript management system is completely online and includes a very quick and fair peer-review system, which is all easy to use. Visit http://www.dovepress.com/ testimonials.php to read real quotes from published authors. 